\title{
They can read all about it: An analysis of global newspaper reporting of genetically modified crop varieties between 1996 and 2013
}

Stephen Morse

Centre for Environmental Strategy, University of Surrey, Guildford, Surrey GU2 7XH, UK

Email: $\underline{\text { S.Morse@ surrey.ac.uk }}$

\begin{abstract}
This paper provides an analysis of the reporting of genetically modified (GM) crop varieties by newspaper across the globe between 1996 and 2013. The aim of the research was to explore whether the significant increase in GM crop area between those years had been paralleled by an increase in press reporting, and if so then whether this was linked to more positive or negative views of the technology. Results suggest that the increase in GM area has been paralleled by an increase in newspaper reporting, and the pattern over time is similar across Africa, Asia, Europe, Latin America, North America and Oceania. Topics typically associated with critiques of GM had significantly lower article counts compared with some that may be associated with more positive visions of GM. Indeed the pattern suggests reporting that is, if anything, mildly positive towards GM up until 2013.
\end{abstract}

Keywords: genetic modification, press reporting,

\section{Introduction}

Research into genetic modification (GM) of plants dates from the 1970s and field trials, under highly controlled conditions, with GM crop varieties took place in the 1980s. The first commercial release of a GM crop (tobacco) was in China in 1992, and the mid 1990s saw a number of GM crop varieties approved for commercial release in the USA and elsewhere (Fedoroff, 2010). Thus at the time of writing the world, or at least parts of it, have experienced the widespread growing of GM crops for nearly 20 years. But this growth in GM has not been without its critics, and indeed the commercial release of GM varieties is still restricted in a number of countries, most notably some within the European Union.

The arguments against the growing of GM crops cover a number of issues (Uzogara, 2000), and indeed were being discussed in the academic literature before the commercial release of a GM crop variety had even taken place; see, for example, the classic analyses provided by Pimental et al. (1989) and Hoffman (1990). The evidence in favour and against commercial growing of GM varieties is strongly contested to this day, and those in favour or against GM crops often quote different studies that provide contradictory evidence or even interpret the same studies in quite different ways. The case in favour of GM crops often revolves around issues such as they may require less pesticide, allow production in marginal areas (such as those subject to drought or salinity) and may enhance the quality of food (better nutritional value, storability). The backdrop for much of this is that the world's population is growing, hence there is a need for more and better food, and GM crops can (but not always) provide higher gross margins for farmers. Critics tend to counter some of these general claims and assumptions by providing examples to the contrary in specific contexts, as well as pointing to potential environmental problems that may result from 'gene release' into the environment, the unknown long-term effects of eating GM food and, of course, the ethics of 'playing God' in this way. The problem, in essence, is that any generalisable claim either for or against GM is always open to attack by finding an exception. Soleri et al. (2008) provide an example of this for what they say is the oft-made claim that farmers in developing countries will always opt for GM varieties as they are 'economically optimal'. In their study in Cuba, Guatemala and 
Mexico this claim was found to be untrue, and this should not be unsurprising given how the local socio-economic and environmental circumstances of farmers can vary so much across space and time. Clearly a claim that GM crops will 'always' be sought after by farmers is bound to be open to dispute, as indeed is any claim that 'all farmers' would benefit economically from growing a GM variety relative to non-GM. Similarly claims that GM crops will 'inevitably' be bad for the environment can be countered by others who can show that this has not been shown to be the case (Conner et al., 2003; Nap et al., 2003). The result is a complex debate of claim and counter-claim that can be hard for a non-specialist to weigh up and assess in terms of risk (Frewer et al., 2004). Perhaps understandably there has been a growing distrust towards actors such as the GM industry and government agencies, and while there have been many calls for a greater degree of engagement with the public so as to elicit their concerns and feed them into the risk management process (Weiner, 2001; Frewer et al., 2004), this remains a challenge.

Needless to say, this maelstrom of claim and counter-claim has had an influence on press reporting of GM crops and in turn has helped influence public opinion (Priest, 2001; Bauer, 2005; Moses, 2015). The role of the media is especially important given that in some countries only a very small proportion of the population is actually engaged in activities linked to agriculture and thus they may rely almost entirely upon what they read or hear in the media (Marks et al., 2003). Hence the media can have great power as both a conduit of information from all sides in the debate as well as taking a position over the relative merits and demerits of GM. Unsurprisingly there have been numerous studies of press reporting of GM crops, both within countries and comparisons across countries, and indeed public attitudes towards the technology and what may be influencing those views (Bauer, 2005; Hughes, 2005; Cook et al., 2006; Shineha et al, 2008; Listerman, 2010; Augoustinos et al., 2010; Flipse and Osseweijer, 2013; Moses, 2015). Frewer et al (2002), for example, explored the 'social amplification of risk' following a spate of mostly negative reports in the UK media in the late 1990s on GM crops (Marks et al., 2003). Indeed the UK media generated the term 'Frankenstein' food which had an immediate and deep resonance with their readership (Horlick-Jones et al., 2007), although some have argued that this impact may have been aided by other factors related to the 'structures' of the GM industry (Schurman, 2004).

While the debate continues to rage between those in favour and against the commercial growing of GM crops the reality is that a number of countries have allowed this to take place for some years and indeed the area under GM crops has been steadily growing since the 1990s. A not-for-profit organisation called the International Service for the Acquisition of Agri-biotech Applications (ISAAA; www.isaaa.org) has been reporting on the global status of GM crop adoption and issues since 1996. The ISAAA estimates that the area planted to GM crop varieties has increased from 27.8 million ha in 1996 (planted by 6 countries) to 170 million ha in 2013 (planted by 27 countries). This represents a 6 fold increase in cropped area and a 4 fold increase in the number of countries in a period of 17 years. Thus it seems reasonable to assume that this change has influenced reporting by the press, especially as the change in area has been different across the globe. This raises two questions:

1. Has the significant increase in GM crop area (and number of countries) been paralleled by an increase in press reporting, perhaps reflecting the benefits and/or concerns that surround the technology? This might be expected for a number of reasons that ironically reflect the advantages and disadvantages of GM as argued by the different camps in the debate, and; 
2. If there has been an increase in press reporting of GM then what issues are discussed in those reports? For example, is there evidence that an increase in reporting reflects a shift towards more positive visions of GM in terms of business and social benefits?

These are, of course, challenging questions to ask given the number of countries that now grow GM crops at commercial scales and the extent and diversity of the global newspaper industry. The analyses of press reporting of GM to date in the academic literature has tended to focus on one (e.g. Cook et al., 2006; Shineha et al., 2008; Augoustinos et al., 2010) or a few countries and rather limited periods of time, typically spanning a few years of intensive debate. The aim with such research is often to compare reporting across a few countries, typically those in the more developed world having quite different stances on commercial release of GM e.g. USA versus countries in the EU (e.g. Botelho and Kurtz, 2008). By way of contrast, there is a dearth of more global analyses of GM press reporting that encompasses other countries besides the North America-EU nexus, and which looks at reporting from the 1990s to the present. It is this gap that the research reported here attempts to fill by addressing the two questions raised above.

\section{Methodology}

Newspapers have a number of advantages over other media in the sense that the articles are archived and can be searched using a number of on-line commercial services. The number of articles reporting GM crops over the period 1996 to 2013 was found using the subscriptionbased Nexis database and search tools available via LexisNexis (internationalsales.lexisnexis.com/english-is/home.page). While the first commercial release of a GM crop (tobacco) took place in 1992 this was only in one country (China) and indeed the variety was withdrawn in 1997. The use of 1996 as a starting point can be defended as this is the year when commercial release of GM varieties began in earnest, with six countries (USA, China, Argentina, Australia, Mexico and Canada) being involved. It is also the first year when estimates of the area planted to GM crops were reported by ISAAA.

The sources selected in the Nexis database were 'All news, All languages' and at the time of the search this spanned a total of 6,760 newspapers in the following languages; Arabic, Danish, Dutch, English, Finnish, French, German, Italian, Malay, Norwegian, Polish, Portuguese, Russian, Spanish, Swedish and Turkish. The newspapers included in the sample of 6,760 titles span the globe and are not restricted to Europe and North America, although no adjustment was made to allow for the extent of readership. For each year the Nexis database was used to return the number of articles per newspaper referring to 'genetically modified crop' at least once in the article. The outputs from the database search are the number of articles (after adjustment for duplication) that have the search term (in this case 'genetically modified crop'). Only one search term was employed, although it could be argued that alternatives such as 'genetically engineered crop', 'transgenic variety' or 'genetically modified plant' could also have been used. It was assumed that 'genetically modified crop' would yield the best returns in terms of number of articles and it is perhaps the phrase that is used most commonly by scientists, industry and indeed critics. Also, whilst the search was across 'all languages' the term 'genetically modified crop' is, of course, English and it is likely that the returns would reflect articles predominantly written in that language and thus introduce an element of bias. It should be noted that the analysis focussed primarily on the patterns of article count across regions rather than the numbers per se.

The number of returns was set to provide the country, countries or regions of focus in the newspaper story (not necessarily the country where the newspaper is published). In some cases the article has no specific country or even regional focus, and in others a number of countries would be mentioned. These outputs were re-categorised, using the United Nations 
geoscheme, into the following regions of Africa, Asia, Europe, Latin America, North America and Oceania.

In addition to the geographical reference the outputs from the database were also set to include the 'topic' (or thrust) of the article. The Nexis database provides many of these but for the purposes of this research only the following seven (as employed in Nexis) were used as broad topics:

- $\quad$ Environment \& Natural Resources

- $\quad$ Ethics

- $\quad$ Government \& Public Administration

- $\quad$ Law \& Legal System

- $\quad$ Safety, Accidents \& Disasters

- $\quad$ Society, Social Welfare \& Lifestyle

- $\quad$ Trade \& Development

These 'topic' or 'issue' categories often appear in the GM literature in one form or another (Scholderer, 2005). Some can be considered to span concerns often raised by critics of GM crops, most notably 'Environment \& Natural Resources', 'Safety, Accidents \& Disasters' and 'Ethics'. For those who promote the advantages of GM crops the categories that may be of most relevance are probably 'Society, Social Welfare \& Lifestyle' and 'Trade \& development'. The other two categories - 'Government \& Public Administration' and 'Law \& legal Systems' are perhaps more neutral in the sense that they largely apply to the approval (or not) and regulation of the technology. But it is readily admitted that these assumptions are somewhat simplistic, and the reliance on the Nexis classification of articles into one or more of these topics is a significant limitation. It was assumed that the Nexis classification of articles via topics and countries did not involve any bias.

The area of GM crops, both global and for the same regions as employed in the Nexis database search, was found from the various reports of the ISAAA published from 1997 (covering the areas for 1996) onwards. A summary of these data is provided in Table 1. An adjustment was made to these data to allow quantitative analysis; any crop area reported as being ' $<0.1$ ha' for a country was changed to 0.1 ha and this probably results in a slight overestimation of GM crops areas at the lower end of the scale. Comparisons between countries and topics in terms of trend over time were made with correlation coefficients. Comparisons between regions and topics in terms of the number of articles were made using the nonparametric Mann-Whitney test.

\section{Results}

Plots of the number of newspaper articles published since 1996 (lines) and the area of GM crops planted for the six regions (bars) are shown in Figure 1 and from this it is visually apparent that some regions are similar in terms of the pattern of article count over time. The latter point is highlighted by the correlation coefficients given in Table 2 . Africa, for example, has a similar pattern to Asia and Latin America ( $r=0.784$ and $r=0.622$, respectively), while North America has a similar pattern to Europe ( $\mathrm{r}=0.948)$, Latin America $(\mathrm{r}=0.802)$ and Oceania ( $\mathrm{r}=0.624)$. Of particular interest are the 'dual spikes' of article count that can be seen in some of the figures, but most notably for North America and Europe. The first of these spans 1999/2000 while the second occurs in 2003. These spikes can also be seen for some of the other regions, but they are not as prominent as for North America and Europe. The 2003 
spike is apparent in the plots for Latin America, Oceania and Africa, and to a far lesser extent in Asia. A third, but less obvious (with the exception of Oceania), 'spike' in reporting can also be seen for 2008 in all six regions. Since 2003 there has been a general trend of increasing article count per year for Africa, Asia and Latin America. For North America and Europe the trend was broadly flat until 2012, with the notable exception of a 'spike' in 2008, after which the article count has shown an increase.

Table 2 also presents the results of a Mann Whitney test comparing the number of articles between regions, and the groups that emerge out of this are shown in Figure 2. Europe has the highest article count (median $=394$ articles/year) followed by North America (median = 186.5 articles/year); this is perhaps not surprising given that these regions have welldeveloped and diverse newspaper industries but also it is in these regions that the debates over GM have arguably been most intense. More surprising at first glance is the low count for the Latin America region (median $=38.5$ articles/year), although the results of the Mann Whitney test put this on a par with Africa (median $=60.5$ articles/year). Given that the extent of GM crop varieties is far greater in Latin America than Africa and Asia, and the fact that the continent is divided in terms of approach taken by countries towards GM, with Argentina, Brazil and Paraguay having most of the GM area and other countries, notably Ecuador and Peru being far more sceptical, then one would perhaps have expected a greater number of newspaper articles. This may, of course, be an artefact of the Nexis database holdings in the sense that newspapers from that continent may be under-represented and it may also reflect the use of an English language (rather than Spanish and Portuguese) search term, but it is nonetheless surprising. It should be noted that the categories of place refer to the emphasis of the article and not necessarily to places where the newspapers were published. If an article published in an EU-based newspaper focussed on GM crops in Latin American country or countries, even if in comparison with a country outside of Latin America, then this would still be classified as 'Latin America' in the Nexis database. In terms of a relationship between GM crop area and number of articles the data suggest a mixed picture. The plots in Figure 1 do suggest a positive relationship between these variables for Africa, Asia and Latin America, although the peaks in reporting noted above do tend to obscure the picture. Nonetheless even with the use of correlation coefficients the relationships between these two variables are 0.762 $(\mathrm{P}<0.001)$ for Africa, $0.79(\mathrm{P}<0.001)$ for Asia and $0.456(\mathrm{P}=0.057)$ for Latin America. For Europe and North America a relationship between cropped area and number of articles is less apparent. For Europe the fact that the GM cropped areas are relatively low may help explain this, but in the case of North America it appears as if the number of articles published per year was more or less constant between 2005 and 2010, notwithstanding a slight peak in 2008.

Trends in article count based on the seven topics are shown as line plots in Figure 3. In each of the graphs the bars represent the global area of GM crops and have been provided for reference. The 'two spike' pattern in reporting identified in Figure 1 (one in the late 1990s and one in 2003/2004) can also be seen for all of the topics in Figure 3, albeit to varying degrees. For some of the topics, most notably 'Safety, Accidents \& Disasters' and 'Society, social welfare and lifestyle' a third, but smaller, peak is discernible for 2008.

The patterns over time across all seven topics do look broadly similar and indeed far more similar than the patterns across regions. This is highlighted by the correlation coefficients in Table 3, all of which (21 out of 21) are statistically significant at $\mathrm{P}<0.05$; in Table 2 (regional comparisons) only 9 out of the 15 correlations were statistically significant at $\mathrm{P}<0.05$.

In fairness it should be noted that similarity in pattern across the topics is perhaps far more likely than similarity in pattern across regions. The topics do overlap to some extent and one may expect a journalist to refer to a number of them in the same article. Thus a discussion of 
'Safety, accidents and disasters' is likely to be accompanied by references to 'Law and Legal Systems' and 'Government and Public Administration'. Similarly an article that talks about the relevance of GM crops for 'Trade and development' is also likely to mention issues of relevance to 'Society, Social Welfare and Lifestyle'. The result has been a degree of multiplecategorisation for each article. For regions there is likely to be weaker correlations given that they have different historical trends in terms of commercial GM release. However, what is perhaps of greater interest with the topics is not so much the pattern over time but the number of articles, and the results of a Mann Whitney test comparing these between topics are also shown in Table 3, along with the median article count. The differences between article counts are substantial, and a summary of the pattern is shown as Figure 4, where the lines indicate groups of topics that are not significantly (at $\mathrm{P}<0.05$ ) different from each other. Here it can be seen that three groups emerge from the analysis, with the group having the highest article count spanning three topics; 'Government and Public Administration' (median = 408), 'Society, Social Welfare and Lifestyle' (median $=403.5$ articles/year) and 'Environment and Natural Resources' (median $=342$ articles/year). Interestingly the group having the smallest article count spans two topics that are likely to be raised by critics of GM; 'Ethics' (median = 76.5 articles/year) and 'Safety, Accidents and Disasters' (median $=71.5$ articles/year).

\section{Discussion}

It first has to be reiterated that the results presented here are only indicative and open up many avenues for future research. The Nexis database provides a valuable resource for searching newspaper articles and cataloguing the results but it is limited in a number of important respects. Firstly, while the number of newspapers included in the database is large and not restricted to those published in English or indeed the more economically developed countries, it is far from being inclusive of all newspapers and the use of just one search term in English would also help to limit the number of articles. It is difficult to come up with a figure as to how many newspapers exist in the world, and indeed much depends on how a newspaper is defined. The Nexis database appears to cover a good proportion of these but coverage may be patchy over time and one is restricted to the definition of a newspaper, and indeed the categorisations, employed by the Nexis developers. Also, of course, it has to be said that newspapers are just one element of media reporting and the world has experienced an explosive growth in other outlets such as the internet and social media. The relevance of these sources within the GM debate certainly warrants further research (Moses, 2015). Secondly there is a question over the reliability of the GM crop area data. The figures employed here are those of ISAAA, and while this is a respected organisation it is funded in part by the GM industry and for critics of the technology this is an important issue. However, it is only fair to point out that the ISAAA data are the best estimates of crop area that are available. Thirdly, grouping all countries together in each region is a weakness of the analysis given that there will probably be major differences between countries in each region. The same point applies, of course, to the grouping of all GM crops together within the search term and it is only to be expected that issues will be different for GM cotton (in essence a non-food crop) and GM brinjal (a food crop) (Herring, 2006).

Nonetheless despite these the results do raise some interesting points in terms of newspaper reporting of the GM debate across the globe. The dominance of Europe and North America in terms of article counts is perhaps unsurprising and indeed comparisons between these places have featured strongly in the existing academic literature, but the lower number of articles related to GM crops in Latin America is perhaps more surprising when one considers the extent and growth of the GM area in that place. The various peaks of newspaper reporting observed between places and indeed topics over time are interesting. Such fluctuations in 
interest are not unusual in the media, of course, and others have noted this effect for the GM debate (Botelho and Kurtz, 2008; Listerman, 2010; Flipse and Osseweijer, 2013). Differences in newspaper reporting have also been noted between countries (Botelho and Kurtz, 2008; Listerman 2010). It is possible to explain some of the peaks in interest seen in these results. The late 1990s peak corresponds with a period of intense debate in Europe over GM crops that followed on from their commercial adoption in the USA in particular. At this time there was a series of environmental and health concerns surrounding GM crops in the EU that eventually resulted in food manufacturers committing to removing all GM-based ingredients in food products and various supermarkets in the EU refusing to sell GM-based products. Non-Governmental Organisations such as Greenpeace had significant anti-GM campaigns in those years, and some countries banned (notably Austria, Italy and France) the importation of GM produce. The pronounced peak in 2003 corresponded with the EU in July of that year adopting a strict and comprehensive set of rules on GM crops, including the requirement for traceability and labelling. Also at this time there were intense discussions over the stance taken by the EU vis-à-vis GM crops at the World Trade Organisation negotiations. However, the reason for a peak in reporting during 2008 to 2009 is less obvious, and there could have been a number of factors at play. One possibility is that the peak in reporting may have been linked to the publication in 2008 of a report by the International Food Policy Research Institute (IFPRI) that rejected the claim that suicides amongst farmers and their families in India were related to the spread of GM varieties. The report did attract a lot of attention at the time, and critics of GM were dismissive of its central findings.

Nonetheless, even with the various spikes in reporting it is noteworthy that a positive correlation existed between the number of articles and the area of GM crops for Africa (0.762; $\mathrm{P}<0.001)$, Asia (0.79; $\mathrm{P}<0.001)$ and to a lesser extent for Latin America $(0.456 ; \mathrm{P}<0.057)$. Clearly as the GM areas increase in those places it would appear that there was increasing discussion in the press and by the end of 2013 there were no signs of this interest waning. For North America, the place with the largest area of GM crops, there is evidence that newspaper interest waned between 2005 and 2010, albeit with a small spike in article count in 2008. Over that same period the area of GM crops continued to increase. A similar pattern was discernible for the EU even though the GM area was far smaller than that in North America and no increase in area occurred over that period. However in both North America and Europe there is some evidence that newspaper reporting started to increase as of 2010.

In terms of topic there are some very interesting patterns that emerge from the analysis. The two aspects of the debate that resonate most with the negative picture of GM, 'Safety, accidents and disasters' and 'Ethics', had the lowest number of article counts. This is surprising as one would have expected these topics to have a stronger presence in terms of newspaper articles given that they often cover the anti-GM discourse. The one topic that has a strong presence in the articles (median $=342$ articles/year) that one would expect to be associated with critiques of GM is 'Environment and natural resources'. It is difficult to generalise, of course, given that 'Safety, accidents and disasters' is also likely to include a strong element of eco-disaster arising from the 'escape' of genes into wild relatives of crop plants, but this is perhaps indicative of a dominance in the anti-GM discourse of environmental impacts.

The strong presence of topics related to 'Government and Public Administration' followed by 'Society, social welfare and lifestyle' is perhaps surprising. Neither of these is obviously related to critiques of GM. 'Government and Public Administration' is perhaps indicative of concerns surrounding the need for legal approval, regulation of field experiments, labelling etc. and may perhaps have some overlap with the 'Law and Legal System' topic. These topics seem to be more neutral towards GM. The 'Society, social welfare and lifestyle' topic would 
seem, if anything, to incorporate more positive aspects to GM crops in the sense of their contributing to development. This is a generalisation, of course, and it is possible that stories within this topic may also discuss the potential negative impacts of GM crops in terms of equity and also debt. As noted above, the latter has been claimed to be an important contributor towards farmer suicides in India (Gruère and Sengupta, 2011).

Overall the picture painted by the article counts with topic categories is not overtly negative towards GM crops, with the possible exception of the 'Environment and natural resources' category. If anything the global picture appears to be neutral to mildly positive. Whether this will continue is another matter. The press tends to reflect both the views of their readership but are also influenced by the views of interest groups, including GM companies, pressure groups, policy makers and politicians. Thus the findings of this research provide a reflection of a complex interplay between the public, press and a wide variety of interests all seeking to have some influence. Newspapers are not just a mirror of society but are part of it and reflect as well as create, although the balance between being a 'conveyor' and 'creator' of news can sometimes be difficult to discern (Vilella-Vila and Costa-Font, 2008). For example, newspapers often carry editorials that set out the views of the editor, and these can often be framed by what is considered to be 'common sense':

“'Common sense' in journalism is a tool for approaching reality and a form of judgment about that reality: expressed in editorials it certainly becomes an important part of sociocultural practice." Rupar (2007: 607).

There is no doubt that newspapers can have a major influence in the debate as witnessed by the 'Frankenfood' stories of the late 1990s (Schurman, 2004), and no doubt such surges will continue. Whether they will have the same amplitude as the surges of 1999 and 2003 is impossible to say, but GM crops are clearly continuing to attract media interest. There are certainly issues of access to the media to consider and this can be different between developed and developing countries (Curtis et al., 2008). It should also be noted that proponents of the technology often bemoan the negativity that surrounds it with regard to agriculture and point to the more favourable response in the media towards more medical applications (Marks et al., 2007) but the inclusion of the environmental dimension is clearly an important distinction between the two.

\section{Conclusions}

The results presented here provide the first analysis of the treatment of GM crops in the global newspaper industry spanning the period from the first extensive planting of GM crops in 1996 to 2013. In terms of a relationship between newspaper reporting and GM crop area the picture is a mixed one, with evidence for a positive relationship in Africa, Asia and Latin America but not elsewhere. In terms of topics there is no strong evidence to suggest that some of those expected to be linked to a strong negative stance regarding GM crops are dominant, with the possible exception of 'Environment and natural resources'. Indeed the pattern suggests reporting that is, if anything, mildly positive towards GM up until 2013.

\section{References}

Augoustinos M, Crabb S and Shepherd R (2010). Genetically modified food in the news: media representations of the GM debate in the UK. Public Understanding of Science 19(1), 98-114.

Bauer MW (2005). Public perceptions and mass media in the biotechnology controversy. International Journal of Public Opinion Research 17(1), 5-22. 
Botelho D and Kurtz H (2008). The introduction of genetically modified food in the United States and the United Kingdom: A news analysis. The Social Science Journal 45, 13-27.

Conner AJ, Glare TR and Nap J-P (2003). The release of genetically modified crops into the environment. Part II. Overview of ecological risk assessment. The Plant Journal 33(1), 19-46.

Cook G, Robbins PT and Pieri E (2006). "Words of mass destruction": British newspaper coverage of the genetically modified food debate, expert and non-expert reactions. Public Understanding of Science 15, 5-29.

Curtis KR, McCluskey JJ and Swinnen JFM (2008). Differences in global risk perceptions of biotechnology and the political economy of the media. International Journal of Global Environmental Issues 8(1/2), 77-89.

Fedoroff NV (2010). The past, present and future of crop genetic modification. New Biotechnology 27(5), 461-465.

Flipse SM and Osseweijer P (2013). Media attention to GM food cases: An innovation perspective. Public Understanding of Science 22(2), 185-202.

Frewer L, Lassen J, Kettlitz B, Scholderer J, Beekman V and Berdal KG (2004). Societal aspects of genetically modified foods. Food and Chemical Toxicology 42, 1181-1193.

Frewer LJ, Miles S and Marsh R (2002). The media and genetically modified foods: Evidence in support of social amplification of risk. Risk Analysis 22(4), 701-711.

Gruère G and Sengupta D (2011). Bt cotton and farmer suicides in India: An evidence-based assessment. The Journal of Development Studies 47(2), 316-337.

Hoffman, CA (1990). Ecological risks of genetic engineering of crop plants. BioScience $40(6), 434+$

Herring, RJ (2006). Why did "Operation Cremate Monsanto" fail? Critical Asian Studies 38, 467-493.

Horlick-Jones T, Walls J, Rowe G, Pidgeon N, Poortinga W, Murdock G and O'Riordan T (2007). The GM Debate: Risk, Politics and Public Engagement. Routledge, Abingdon.

Hughes, E (2005). The contaminated risk of GM crops: nationalism and the genetic modification debate. Journal of Public Affairs 5(3-4), 251-262.

Listerman T (2010). Framing of science issues in opinion-leading news: International comparison of biotechnology issue coverage. Public Understanding of Science 19(1), 5-15.

Marks LA, Kalaitzandonakes N, Allison K and Zakharova L (2003). Media coverage of agrobiotechnology: Did the butterfly have an effect? Journal of Agribusiness 21(1), 1-20.

Marks LA, Kalaitzandonakes N, Wilkins L and Zakharova L (2007). Mass media framing of biotechnology news. Public Understanding of Science 16, 183-203.

Moses, V (2015). GM crops in the media. GM Crops \& Food 6(1), 1-12.

Nap J-P, Metz PLJ, Escaler M and Conner AJ (2003). The release of genetically modified crops into the environment. Part I. Overview of current status and regulations. The Plant Journal 33(1), pages 1-18.

Pimentel D, Hunter MS, LaGro JA, Efroymson RA, Landers JC, Mervis FT, McCarthy CA and Boyd AE (1989). Benefits and risks of genetic engineering in agriculture. BioScience 39(9), 606-614. 
Priest SH (2001). A Grain of Truth: The Media, the Public, and Biotechnology. Rowman and Littlefield, Lanham, Maryland.

Rupar V (2007). Newspapers' production of common sense. The 'greenie madness' or why should we read editorials? Journalism 8(5), 591-610.

Scholderer J (2005). The GM foods debate in Europe: history, regulatory solutions, and consumer response research. Journal of Public Affairs 5, 263-274.

Schurman R (2004). Fighting "Frankenfoods": Industry Opportunity Structures and the Efficacy of the Anti-Biotech Movement in Western Europe. Social Problems 51(2), 243-268.

Shineha R, Hibino A and Kato K (2008). Analysis of Japanese newspaper articles on genetic modification. Journal of Science Communication 7(2), 1-9.

Soleri D, Cleveland DA, Glasgow G, Sweeney SH, Cuevas FA, Fuentes MR, Ríos L. H (2008). Testing assumptions underlying economic research on transgenic food crops for Third World farmers: Evidence from Cuba, Guatemala and Mexico. Ecological Economics 67(4), $667-682$.

Uzogara SG (2000). The impact of genetic modification of human foods in the 21st century: A review. Biotechnology Advances 18, 179-206.

Vilella-Vila $\mathrm{M}$ and Costa-Font $\mathrm{J}$ (2008). Press media reporting effects on risk perceptions and attitudes towards genetically modified (GM) food. The Journal of Socio-Economics 37(5), 2095-2106.

Weiner C (2001). Drawing the line in genetic engineering: Self-regulation and public participation. Perspectives in Biology and Medicine 44(2), 208-220. 
Table 1. Global area (million ha) by country under GM crops from 1996 to 2013 as reported by ISAAA.

\begin{tabular}{|c|c|c|c|c|c|c|c|c|c|c|c|c|c|c|c|c|c|c|}
\hline Country & 1996 & 1997 & 1998 & 1999 & 2000 & 2001 & 2002 & 2003 & 2004 & 2005 & 2006 & 2007 & 2008 & 2009 & 2010 & 2011 & 2012 & 2013 \\
\hline USA & 1.5 & 8.1 & 20.5 & 28.7 & 30.3 & 35.7 & 39 & 42.8 & 47.6 & 49.8 & 54.6 & 57.7 & 62.5 & 64 & 66.8 & 69 & 69.5 & 70.1 \\
\hline Brazil & & & & & & & & 3 & 5 & 9.4 & 11.5 & 15 & 15.8 & 21.4 & 25.4 & 30.3 & 36.6 & 40.3 \\
\hline Argentina & 0.1 & 1.4 & 4.3 & 6.7 & 10 & 11.8 & 13.5 & 13.9 & 16.2 & 17.1 & 18 & 19.1 & 21 & 21.3 & 22.9 & 23.7 & 23.9 & 24.4 \\
\hline Canada & 0.1 & 1.3 & 2.8 & 4 & 3 & 3.2 & 3.5 & 4.4 & 5.4 & 5.8 & 6.1 & 7 & 7.6 & 9.2 & 8.8 & 10.4 & 11.6 & 10.8 \\
\hline India & & & & & & & $<0.1$ & 0.1 & 0.5 & 1.3 & 3.8 & 6.2 & 7.6 & 8.4 & 9.4 & 10.6 & 10.8 & 11 \\
\hline China & 1.1 & 1.8 & $<0.1$ & 0.3 & 0.5 & 1.5 & 2.1 & 2.8 & 3.7 & 3.3 & 3.5 & 3.8 & 3.8 & 3.7 & 3.5 & 3.9 & 4 & 4.2 \\
\hline Paraguay & & & & & & & & & 1.2 & 1.8 & 2 & 2.6 & 2.7 & 2.2 & 2.6 & 2.8 & 3.4 & 3.6 \\
\hline South Africa & & & $<0.1$ & 0.1 & 0.2 & 0.2 & 0.3 & 0.4 & 0.5 & 0.5 & 1.4 & 1.8 & 1.8 & 2.1 & 2.2 & 2.3 & 2.9 & 2.9 \\
\hline Pakistan & & & & & & & & & & & & & & & 2.4 & 2.6 & 2.8 & 2.8 \\
\hline Uruguay & & & & & $<0.1$ & $<0.1$ & $<0.1$ & $>0.05$ & 0.3 & 0.3 & 0.4 & 0.5 & 0.7 & 0.8 & 1.1 & 1.3 & 1.4 & 1.5 \\
\hline Bolivia & & & & & & & & & & & & & 0.6 & 0.8 & 0.9 & 0.9 & 1 & 1 \\
\hline Philippines & & & & & & & & $<0.05$ & 0.1 & 0.1 & 0.2 & 0.3 & 0.4 & 0.5 & 0.5 & 0.6 & 0.8 & 0.8 \\
\hline Indonesia & & & & & & $<0.1$ & $<0.1$ & $<0.05$ & & & & & & & & & & \\
\hline $\begin{array}{l}\text { Australia } \\
\text { Burkina }\end{array}$ & $<0.1$ & 0.1 & 0.1 & 0.1 & 0.2 & 0.2 & 0.1 & 0.1 & 0.2 & 0.3 & 0.2 & 0.1 & 0.2 & 0.2 & 0.7 & 0.7 & 0.7 & 0.6 \\
\hline Faso & & & & & & & & & & & & & $<0.1$ & 0.1 & 0.3 & 0.3 & 0.3 & 0.5 \\
\hline Myanmar & & & & & & & & & & & & & & & 0.3 & 0.3 & 0.3 & 0.3 \\
\hline Mexico & $<0.1$ & $<0.1$ & $<0.1$ & $<0.1$ & $<0.1$ & $<0.1$ & $<0.1$ & $<0.05$ & 0.1 & 0.1 & 0.1 & 0.1 & 0.1 & 0.1 & 0.1 & 0.2 & 0.2 & 0.1 \\
\hline Spain & & & $<0.1$ & $<0.1$ & $<0.1$ & $<0.1$ & $<0.1$ & $<0.05$ & 0.1 & 0.1 & 0.1 & 0.1 & 0.1 & 0.1 & 0.1 & 0.1 & 0.1 & 0.1 \\
\hline Chile & & & & & & & & & & & & $<0.1$ & $<0.1$ & $<0.1$ & $<0.1$ & $<0.1$ & $<0.1$ & $<0.1$ \\
\hline Colombia & & & & & & & $<0.1$ & $<0.05$ & $<0.05$ & $<0.1$ & $<0.1$ & $<0.1$ & $<0.1$ & $<0.1$ & $<0.1$ & $<0.1$ & $<0.1$ & 0.1 \\
\hline Honduras & & & & & & & $<0.1$ & $<0.05$ & $<0.05$ & $<0.1$ & $<0.1$ & $<0.1$ & $<0.1$ & $<0.1$ & $<0.1$ & $<0.1$ & $<0.1$ & $<0.1$ \\
\hline Sudan & & & & & & & & & & & & & & & & $<0.1$ & $<0.1$ & 0.1 \\
\hline Portugal & & & & $<0.1$ & & & & & & $<0.1$ & $<0.1$ & $<0.1$ & $<0.1$ & $<0.1$ & $<0.1$ & $<0.1$ & $<0.1$ & $<0.1$ \\
\hline Ukraine & & & & $<0.1$ & & & & & & & & & & & & & & \\
\hline Czech & & & & & & & & & & & & & & & & & & \\
\hline Republic & & & & & & & & & & $<0.1$ & $<0.1$ & $<0.1$ & $<0.1$ & $<0.1$ & $<0.1$ & $<0.1$ & $<0.1$ & $<0.1$ \\
\hline
\end{tabular}


Cuba

\section{Egypt}

Costa Rica

Romania

Bulgaria

Slovakia

Poland

Iran

Sweden

Germany

France

Total area

Number of

countries

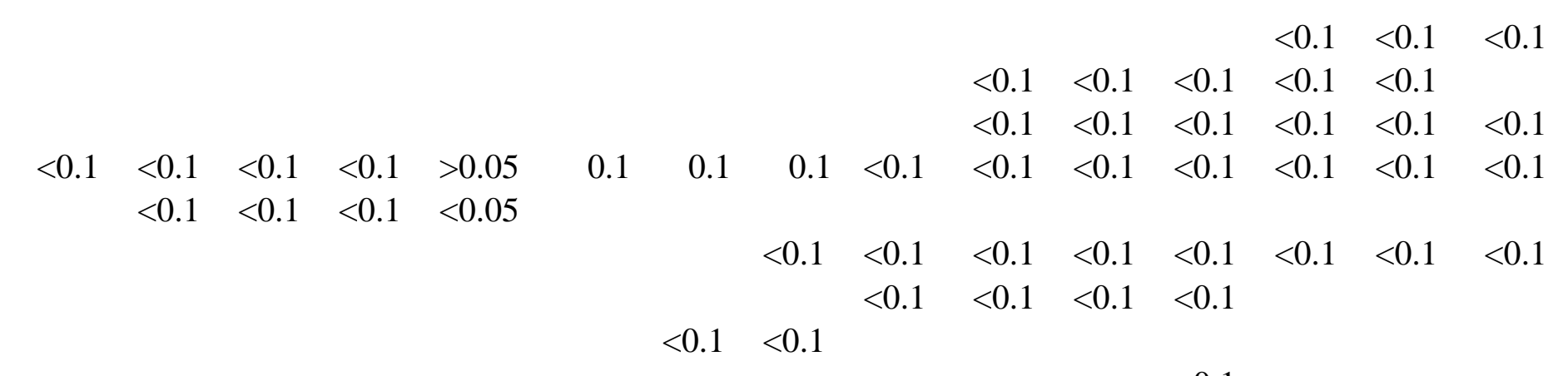

$\begin{array}{ccccccccc}<0.1 & <0.1 & <0.1 & <0.05 & <0.05 & <0.1 & <0.1 & <0.1 & <0.1\end{array}$

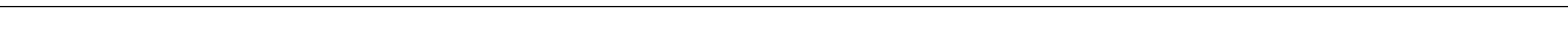

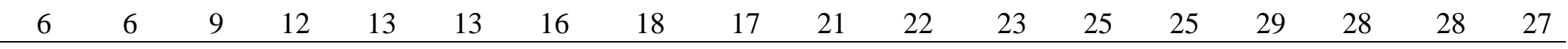


Table 2. Correlation coefficients (top figure) and MannWhitney statistics (bottom figure) comparing the newspaper article counts across regions.

\begin{tabular}{|c|c|c|c|c|c|c|c|}
\hline & $\begin{array}{l}\text { Median } \\
\text { article } \\
\text { count }\end{array}$ & Africa & Asia & Europe & Latin America & $\begin{array}{c}\text { North } \\
\text { America }\end{array}$ & Oceania \\
\hline Median article count & & 60.5 & 110 & 394 & 38.5 & 186.5 & 116.5 \\
\hline Africa & 60.5 & 1 & $\begin{array}{c}0.784 * * * \\
279.5 \mathrm{~ns}\end{array}$ & $\begin{array}{c}0.149 \mathrm{~ns} \\
203.5 * * *\end{array}$ & $\begin{array}{c}0.622 * * \\
392 \mathrm{~ns}\end{array}$ & $\begin{array}{l}0.381 \mathrm{~ns} \\
231.5 * *\end{array}$ & $\begin{array}{c}0.320 \mathrm{~ns} \\
266 *\end{array}$ \\
\hline Asia & 110 & & 1 & $\begin{array}{c}0.168 \mathrm{~ns} \\
222.5 * * *\end{array}$ & $\begin{array}{l}0.643 * * \\
440 * * *\end{array}$ & $\begin{array}{l}0.434 \mathrm{~ns} \\
272.5 \mathrm{~ns}\end{array}$ & $\begin{array}{c}0.155 \mathrm{~ns} \\
320 \mathrm{~ns} \\
\end{array}$ \\
\hline Europe & 394 & & & 1 & $\begin{array}{l}0.666 * * \\
465 * * *\end{array}$ & $\begin{array}{c}0.948 * * * \\
412.5 *\end{array}$ & $\begin{array}{c}0.625 * * \\
456 * * *\end{array}$ \\
\hline Latin America & 38.5 & & & & 1 & $\begin{array}{l}0.802 * * * \\
212.5 * * *\end{array}$ & $\begin{array}{c}0.508 * \\
219.5 * * *\end{array}$ \\
\hline North America & 186.5 & & & & & 1 & $\begin{array}{c}0.624 * * \\
397 *\end{array}$ \\
\hline Oceania & 116.5 & & & & & & 1 \\
\hline
\end{tabular}

Correlation coefficient $\mathrm{df}=16$

ns $=$ not significant at 0.05

$* \mathrm{P}<0.05$

$* * \mathrm{P}<0.01$

$* * * \mathrm{P}<0.001$ 
Table 3. Correlation coefficients (top figure) and MannWhitney statistics (bottom figure) comparing the newspaper article counts across topics.

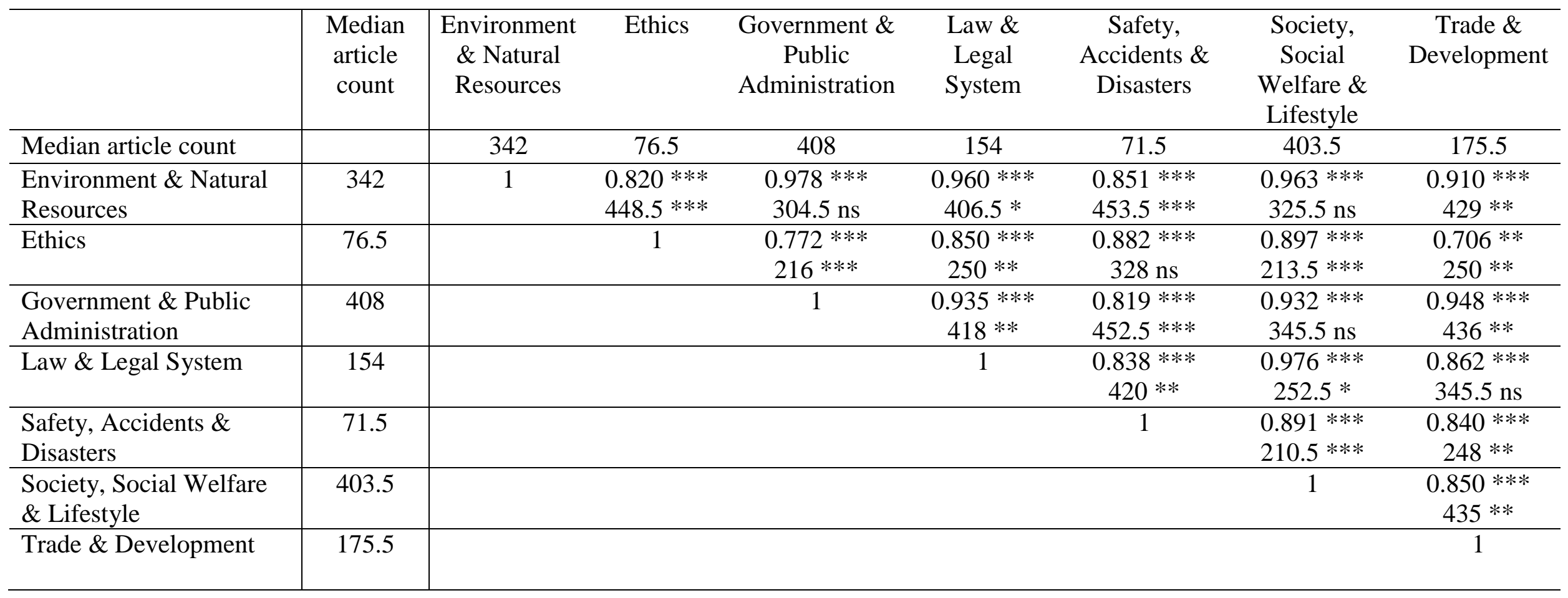

Correlation coefficient $\mathrm{df}=16$

ns $=$ not significant at 0.05

$* \mathrm{P}<0.05$

** $\mathrm{P}<0.01$

$* * * \mathrm{P}<0.001$ 
Figure 1. Relationship between number of newspaper articles focussed on a particular region and the GM crop area for that region.

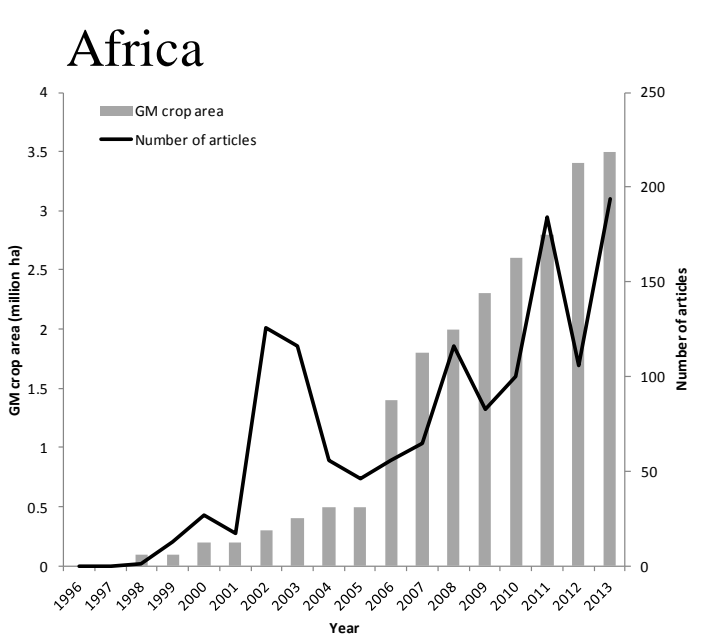

$$
\text { Asia }
$$

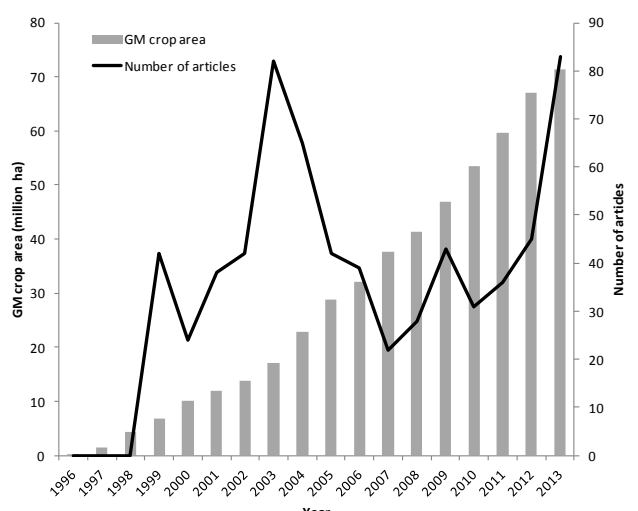

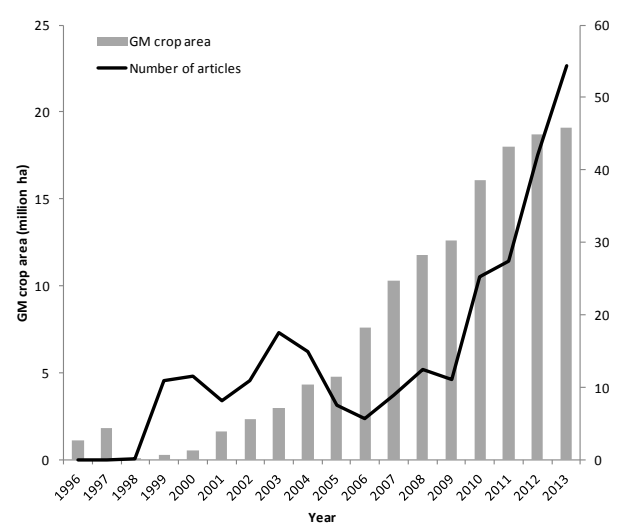

North America

\section{Europe}

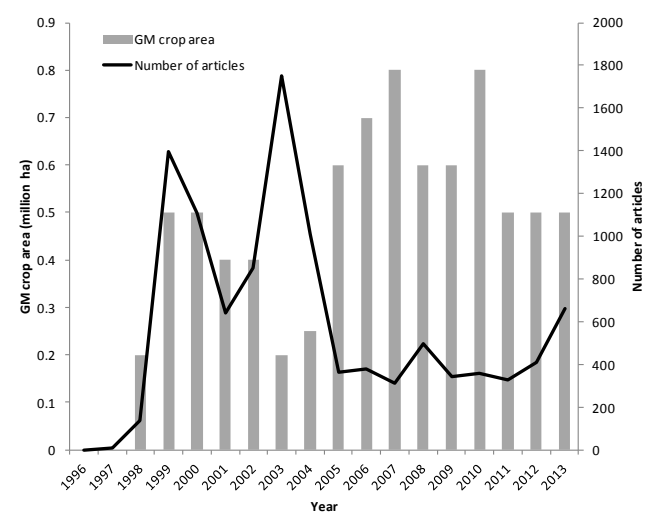

\section{Oceania}

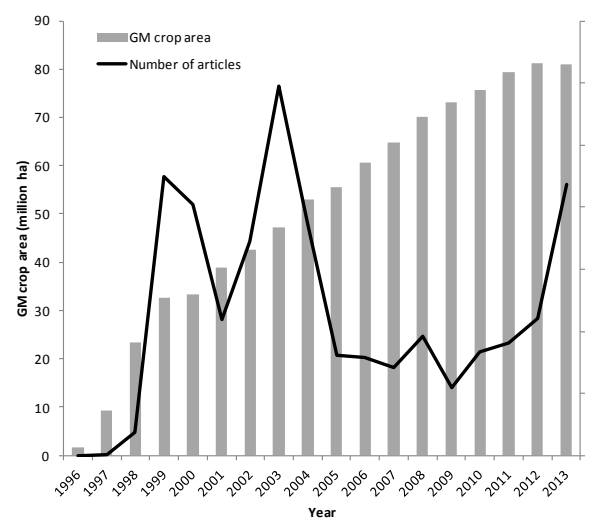

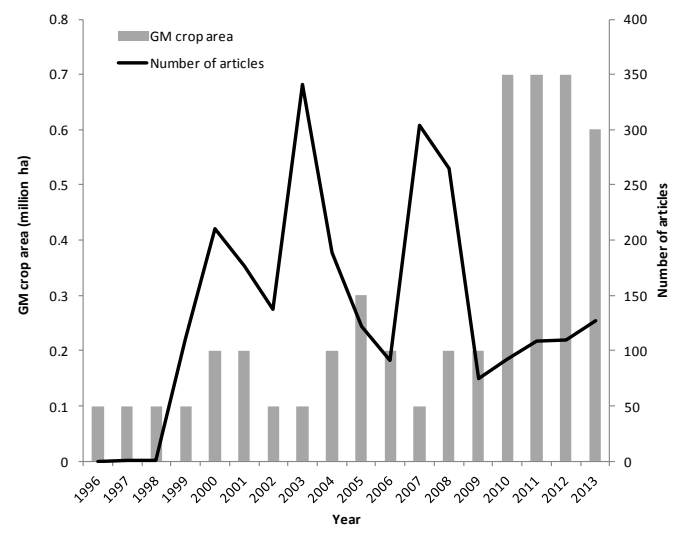


Figure 2. Groupings of regions used for classifying articles. Solid bar represents regions where the medians are not significantly different (using the Mann Whitney test results from Table 2).

$\begin{array}{lc}\text { Region } & \text { Median count } \\ \text { Europe } & 394 \\ \text { North America } & 186.5 \\ \text { Oceania } & 116.5 \\ \text { Asia } & 110 \\ \text { Africa } & 60.5 \\ & \\ \text { Latin America } & 38.5\end{array}$


Figure 3. Relationship between number of newspaper articles focussed on a particular topic and the global GM crop area.

Environment and Natural Resources

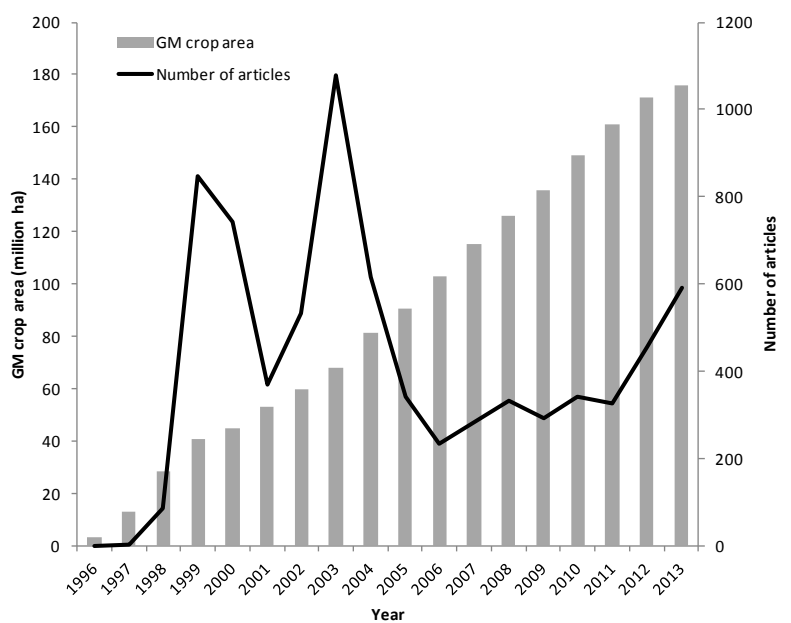

Safety, accidents and disasters

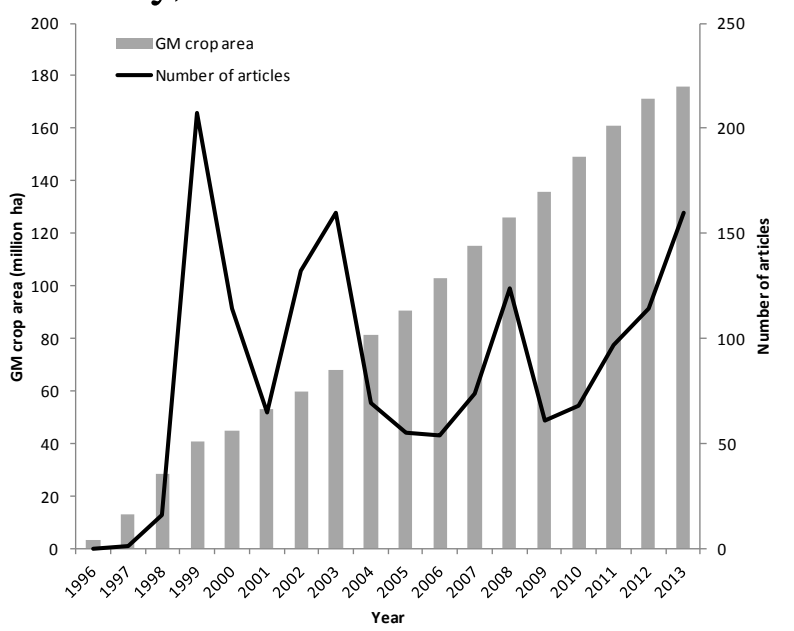

\section{Ethics}

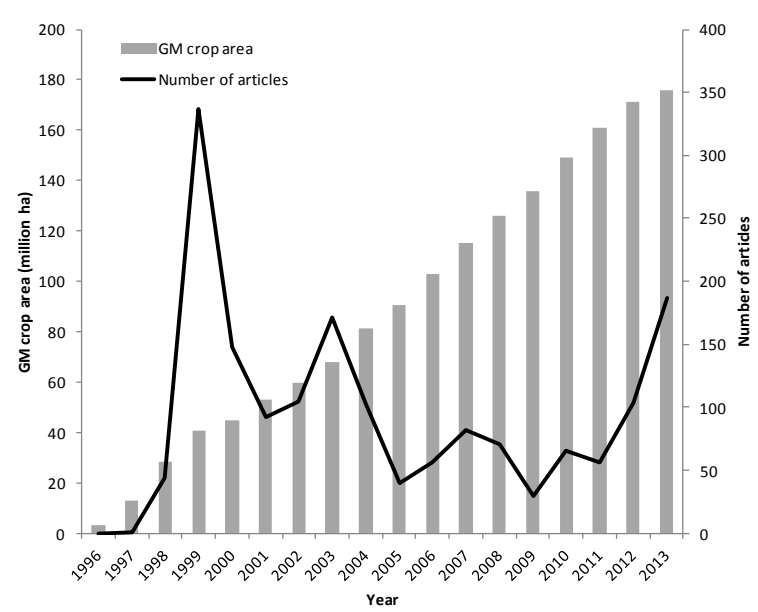


Figure 3 (continued). Relationship between number of newspaper articles focussed on a particular topic and the global GM crop area.

Trade and development

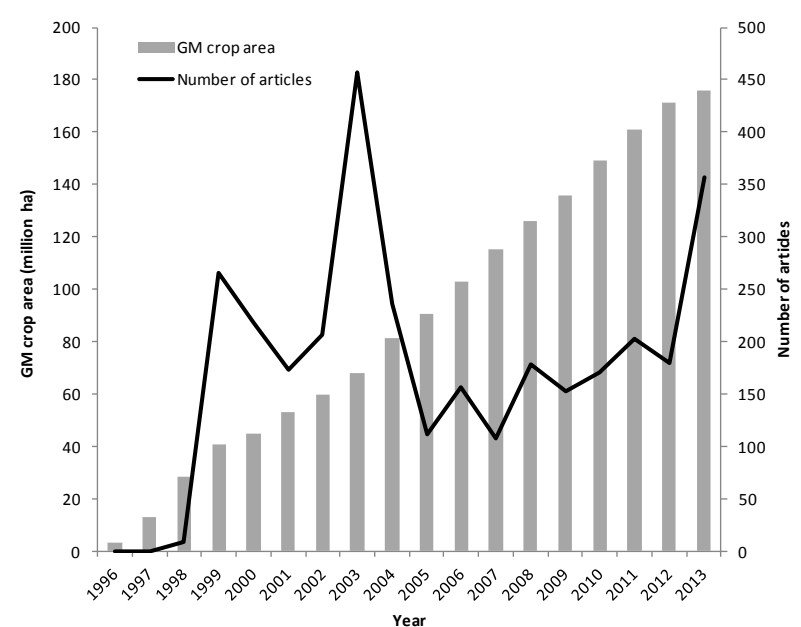

Government and Public Administration

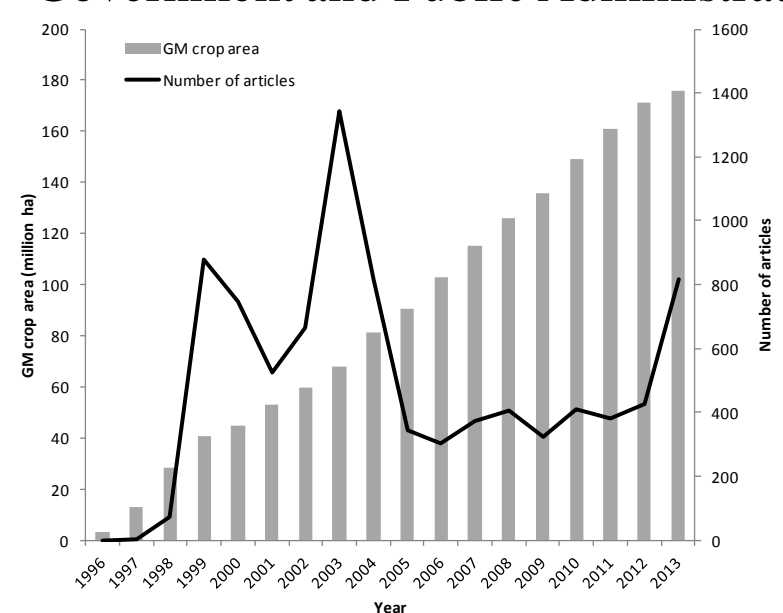

Society, social welfare and lifestyle

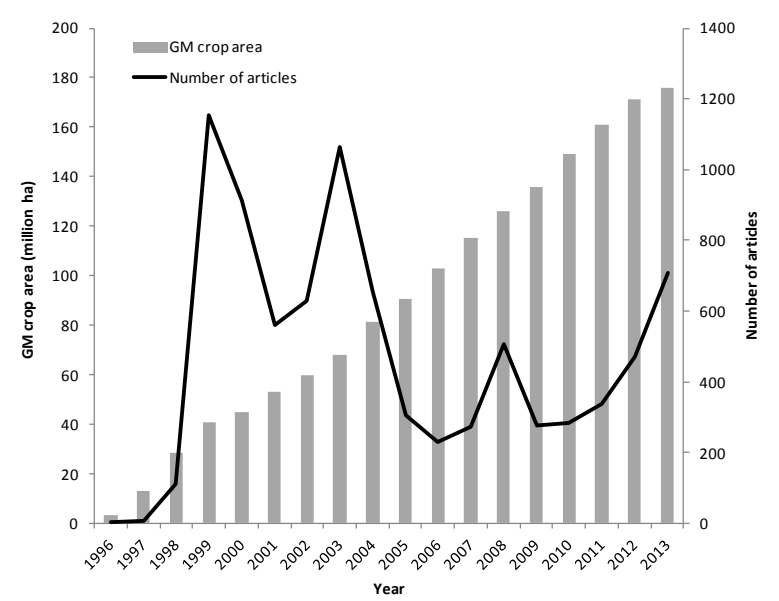

Law and Legal System

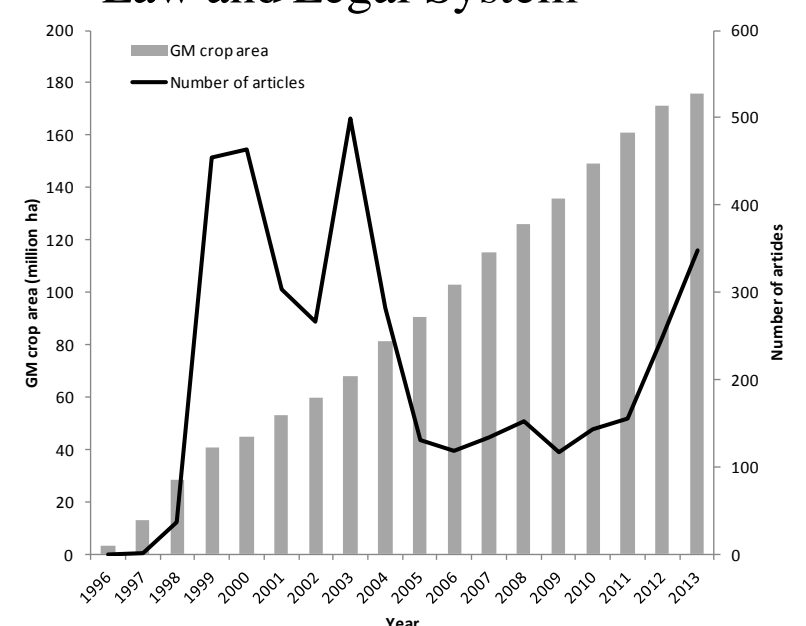


Figure 4. Groupings of topic used for classifying articles. Solid bar represents topics where the medians are not significantly different (using the Mann Whitney test results from Table 3).

Topic

Government \& Public Administration

Society, Social Welfare \& Lifestyle

Environment \& Natural Resources

Trade \& Development

Law \& Legal System

Ethics

Safety, Accidents \& Disasters

Median count
408
403.5
342
175.5
154
76.5
71.5

